\title{
Detection and Quantification Methods for Viable but Non-culturable (VBNC) Cells in Process Wash Water of Fresh-Cut Produce: Industrial Validation
}

\section{OPEN ACCESS}

Edited by:

Nguyen Thi Thanh Hanh, Seoul National University,

South Korea

Reviewed by:

Dimitris Tsaltas,

Cyprus University of Technology,

Cyprus

Xiaomei Su,

Zhejiang Normal University, China

*Correspondence: Pilar Truchado ptruchado@cebas.csic.es

Specialty section: This article was submitted to

Food Microbiology,

a section of the journal

Frontiers in Microbiology

Received: 16 January 2020 Accepted: 24 March 2020 Published: 04 May 2020

Citation:

Truchado P, Gil MI, Larrosa M and Allende A (2020) Detection and Quantification Methods for Viable but Non-culturable (VBNC) Cells in Process Wash Water of Fresh-Cut

Produce: Industrial Validation.

Front. Microbiol. 11:673. doi: 10.3389/fmicb.2020.00673

\author{
Pilar Truchado ${ }^{1 *}$, Maria I. Gil' ${ }^{1}$ Mar Larrosa² and Ana Allende ${ }^{1}$ \\ ${ }^{1}$ Research Group on Quality, Safety and Bioactivity of Plant Foods, The Centre of Edafology and Applied Biology of Segura, \\ Spanish National Research Council (CEBAS-CSIC), Murcia, Spain, ${ }^{2}$ Faculty of Biomedical and Health Sciences, Nutrition, \\ Microbiota and Health Group, Universidad Europea de Madrid, Villaviciosa de Odón, Madrid, Spain
}

The significance of viable but non-culturable (VBNC) cells in the food industry is not well known, mainly because of the lack of suitable detection methodologies to distinguish them from dead cells. The study aimed at the selection of the method to differentiate dead and VBNC cells of Listeria monocytogenes in process wash water (PWW) from the fruit and vegetable industry. Different methodologies were examined including (i) flow cytometry, (ii) viability quantitative polymerase chain reaction (v-qPCR) using an improved version of the propidium monoazide (PMAxx) dye as DNA amplificatory inhibitor, and (iii) v-qPCR combining ethidium monoazide (EMA) and PMAxx. The results showed that the flow cytometry, although previously recommended, was not a suitable methodology to differentiate between dead and VBNC cells in PWW, probably because of the complex composition of the water, causing interferences and leading to an overestimation of the dead cells. Based on results obtained, the v-qPCR combined with EMA and PMAxx was the most suitable technique for the detection and quantification of VBNC cells in PWW. Concentrations of $10 \mu \mathrm{M}$ EMA and $75 \mu \mathrm{M}$ PMAxx incubated at $40^{\circ} \mathrm{C}$ for 40 min followed by a 15 -min light exposure inhibited most of the $\mathrm{qPCR}$ amplification from dead cells. For the first time, this methodology was validated in an industrial processing line for shredded lettuce washed with chlorine $(10 \mathrm{mg} / \mathrm{L})$. The analysis of PWW samples allowed the differentiation of dead and VBNC cells. Therefore, this method can be considered as a rapid and reliable one recommended for the detection of VBNC cells in complex water matrixes such as those of the food industry. However, the complete discrimination of dead and VBNC cells was not achieved, which led to a slight overestimation of the percentage of VBNC cells in PWW, mostly, due to the complex composition of this type of water. More studies are needed to determine the significance of VBNC cells in case of potential cross-contamination of fresh produce during washing.

Keywords: flow cytometry, quantitative PCR, microbial inactivation, food safety, Listeria monocytogenes 


\section{INTRODUCTION}

Several studies have evidenced that many bacterial species, including foodborne pathogenic bacteria, develop stress resistance mechanisms that enable them to enter into a temporary state of low metabolic activity (Oliver, 2010). Under these conditions, cells can persist for extended periods without division, called dormancy or a viable but non-culturable (VBNC) state. The VBNC state has been defined as a survival strategy, where bacteria cannot grow on routine culture media but are alive and capable of renewing metabolic activity (Zhao et al., 2017; Dong et al., 2020). Recently, Dong et al. (2020) demonstrated that cells in the VBNC state go through different changes, including morphological and compositional variations, which allow them to have a higher resistance to chemical and physical stresses. Viable but non-culturable cells maintain their intact cell membrane and are metabolically active, to continue gene expression, having the ability to become culturable once resuscitated (Fida et al., 2017; Su et al., 2019). The occurrence of VBNC bacterial pathogens in food has been identified as a public risk concern (Makino et al., 2000). The presence of VBNC enterohemorrhagic Escherichia coli in salmon has been liked to a food poisoning incident (Dong et al., 2020). However, the significance of VBNC cells in the food industry related to cross-contamination during processing has not been elucidated, mostly because the available methodologies cannot differentiate dead and VBNC cells correctly in different matrixes. Therefore, there is a need to optimize the detection and quantification methods in different matrixes. Process wash water (PWW) has been recognized as one of the relevant vectors of microbial cross-contamination in the agro-food industries (Gil and Allende, 2018). Cross-contamination occurs when a contaminated product is washed and the pathogens are transferred from the contaminated product to the water and from the water to the clean product. Sanitizers are needed to maintain the microbiological quality of PWW, avoiding cross-contamination (Gombas et al., 2017). Chlorine is the most common sanitizer in the fresh produce industry. Generally, the efficacy of the sanitizers has been evaluated using plate counts (López-Gálvez et al., 2019). However, recently, Highmore et al. (2018) have demonstrated that chlorine induces the VBNC state of the foodborne pathogens Listeria monocytogenes and Salmonella enterica. Optimized quantification methods are required to determine the significance of the presence of VBNC cells in PWW.

The most popular methods to determine the presence and concentration of VBNC cells are staining techniques (Zhao et al., 2017). These techniques are based on the cell membrane integrity to differentiate between dead and VBNC cells, assuming that dead cells have the membrane damaged while VBNC and viable cells have an intact membrane (Oliver, 2010). However, as not all the dead cells have their cell membrane compromised, these methods can lead to an overestimation in the number of VBNC cells. The combination of dyes and flow cytometry has been widely used to determine the cell viability of foodborne pathogenic bacteria (Léonard et al., 2016), but it is not suitable for all the matrixes. Instead, viability quantitative polymerase chain reaction ( $\mathrm{v}-\mathrm{qPCR}$ ) has been widely adopted to detect and quantify the presence of viable bacteria in specific food matrixes and water (Truchado et al., 2016; Dorn-In et al., 2019). The quantitative real-time PCR (qPCR) methodology has been combined with the use of photoreactive dyes such as propidium monoazide (PMA) and ethidium monoazide (EMA), as PMA-qPCR in food matrix and water (Codony et al., 2015). This technique is based on the ability of PMA to penetrate the dead cells which compromised membrane integrity and bind covalently to the DNA and free DNA after photoactivation, thus preventing subsequent PCR amplification (Nocker et al., 2006). On the other hand, EMA can diffuse across cell membranes using efflux pumps (Codony et al., 2015). However, these methodologies have to be validated for each type of matrix to avoid overestimation of the VBNC cells due to the presence of dead cells with an intact membrane (Nocker and Camper, 2009).

The objective of the present study was to optimize a suitable detection and quantification method of VBNC cells in PWW and the food safety significance for the agro-food industry. Different methodologies were examined, including (i) combination of dyes and flow cytometry; (ii) v-qPCR using PMAxx, an improved version of the PMA dye; and (iii) $\mathrm{v}$-qPCR combining EMA and PMAxx. Additionally, the selected methodology was validated for the first time under industrial settings for PWW treated with chlorine. These studies were performed using L. monocytogenes as a model foodborne pathogen, which has been described to enter into the VBNC state (Highmore et al., 2018) and linked to listeriosis outbreaks in fresh produce (European Food Safety Authority [EFSA], 2018).

\section{MATERIALS AND METHODS}

\section{Bacterial Strains and Cocktail Preparation}

For the inoculation of PWW, a six-strain cocktail of L. monocytogenes was used in this study. Strains were isolated from leafy vegetables, as previously described (Truchado et al., 2020). The L. monocytogenes strains were reconstituted in Brain Heart Infusion (BHI) broth (Oxoid, Basingstoke, United Kingdom) and consecutively subcultured twice in $10 \mathrm{ml}$ of $\mathrm{BHI}$, the first time at $37^{\circ} \mathrm{C}$ for $24 \mathrm{~h}$ and the second time at $37^{\circ} \mathrm{C}$ for $16 \mathrm{~h}$. After the second incubation, $1 \mathrm{ml}$ of each strain was combined to obtain a six-strain cocktail of L. monocytogenes $\left(10^{9} \mathrm{cfu} / \mathrm{ml}\right)$.

To assay the suitability of detection methods to differentiate dead and VBNC cells, bacterial suspensions of dead and viable cells $\left(10^{9} \mathrm{cfu} / \mathrm{ml}\right)$ were prepared as follows:

1. Heat treatment: The L. monocytogenes cocktail was exposed at $85^{\circ} \mathrm{C}$ for $20 \mathrm{~min}$ using a laboratory standard heat block.

2. Sanitizing treatment: Sodium hypochlorite was added to the six-strain cocktail of $L$. monocytogenes until a residual of $10 \mathrm{mg} / \mathrm{l}$ of free chlorine was reached to guarantee the complete inactivation of the cells. After a 1-min exposure time, 0.3 M of sodium thiosulfate pentahydrate (Scharlau, Barcelona, Spain) was added to quench the residual chlorine. 
Free chlorine concentration was measured with a digital chlorine colorimeter kit (DPD method; LaMotte model DC 1100, Chestertown, MD).

The cell inactivation after the treatments was confirmed by plating serial suspension dilutions of the treated L. monocytogenes cocktail in buffered peptone water (BPW, $2 \mathrm{~g} / \mathrm{l}$; Oxoid, Basingstoke, United Kingdom) on Oxford agar (Scharlau, Barcelona, Spain) followed by incubation at $37^{\circ} \mathrm{C}$ for $24 \mathrm{~h}$. To inoculate PWW, the initial six-strain cocktail of $L$. monocytogenes $\left(10^{9} \mathrm{cfu} / \mathrm{ml}\right)$ was centrifuged at $2,500 \mathrm{~g}$ for $5 \mathrm{~min}$, and the supernatant was eliminated. The obtained pellet was washed twice with $18 \mathrm{ml}$ of phosphate-buffered saline (PBS; Scharlau, Barcelona, Spain) using the same conditions as above. The cocktail was added to PWW to reach the desired concentration of approximately $10^{5} \mathrm{cfu} / \mathrm{ml}$. The final concentration of the inoculum in the PWW was confirmed by plating duplicate serial suspension dilutions on ALOA/OCLA agar (Scharlau, Barcelona, Spain) followed by incubation at $37^{\circ} \mathrm{C}$ for $24 \mathrm{~h}$.

\section{PWW Generated at Laboratory Scale}

Process wash water from washing shredded lettuce was generated in the laboratory, mimicking the industrial conditions previously described (Tudela et al., 2019). Organic matter was measured as chemical oxygen demand (COD) determined by the standard photometric method (APHA, 1998) using the Spectroquant NOVA 60 photometer. The COD of the PWW was $1,700 \mathrm{mg} / \mathrm{l}$.

\section{Live/Dead Flow Cytometry Analysis}

Cell viability was determined by flow cytometry (LSRFortessa X-20 system) using the Live/Dead BacLight ${ }^{\circledR}$ bacterial viability kit (Invitrogen, Waltham, United States) that contains two nucleic acid stains with different abilities to penetrate the bacterial cells: SYTO 9 and propidium iodine (PI). SYTO 9 is a cell-permeant green fluorescent dye that enters both live and dead cells. Propidium iodine is a membrane-impermeant dye that penetrates only in damaged or dead cells and emits red fluorescence upon intercalation with double-stranded DNA. When both dyes are used simultaneously, SYTO 9 is replaced by PI due to its higher affinity to bind DNA, quenching SYTO 9 fluorescence signal (Stiefel et al., 2015). As a result, red signals from cells are considered as "dead," green signals as "alive," and the double-staining cells as an intermediate state of membrane-compromised cells. The staining procedure was performed according to the manufacturer's instructions.

Flow cytometry was used for measuring the viability of L. monocytogenes cells inoculated in PWW after treatment with chlorine. Untreated inoculated samples of PWW $(50 \mathrm{ml})$ were used as controls and compared with inoculated PWW treated with $10 \mathrm{mg} / \mathrm{l}$ of free chlorine. This treatment reproduces the conditions found in industrial washing tanks. One milliliter of each PWW was mixed with $3 \mu$ l of both dyes ( $5 \mu \mathrm{M}$ SYTO 9 and $30 \mu \mathrm{M}$ PI) incubated for $15 \mathrm{~min}$ at room temperature in the dark. The green fluorescence emission of live bacteria was detected in the cytometer at $520 \mathrm{~nm}$ (FL1 channel), while the red fluorescence emission of compromised (double-stained) or dead bacteria was detected at $630 \mathrm{~nm}$ (FL4 channel). During data acquisition, all parameters were collected in the log mode, and data analysis was performed with the EC800 software version 1.3.6. (Sony Biotechnology Inc., Champaign, IL, United States). Forward and side scatter gates were established to exclude debris. Unstained and stained untreated live L. monocytogenes and isopropanol $70 \%$ dead L. monocytogenes were used as controls for gating the different regions and fluorescence adjustment.

\section{PMAxx v-qPCR}

PMAxx (Biotium, Hayward, CA, United States), an improved version of the PMA dye for the selective detection of live bacteria by $\mathrm{qPCR}$, was used as follows. PMAxx was diluted in sterile water to obtain a $2 \mathrm{mM}$ stock solution and stored at $-20^{\circ} \mathrm{C}$ in the dark until used. Separate flasks of PWW $(50 \mathrm{ml})$ were inoculated with a cocktail of L. monocytogenes containing live (exponential phase), heat-treated, and chlorine-treated cells to approximately $10^{4} \mathrm{cfu} / \mathrm{ml}$. From each flask, $10 \mathrm{ml}$ of PWW was centrifuged at $4,000 \mathrm{rpm}$ for $10 \mathrm{~min}$ at $4^{\circ} \mathrm{C}$. The supernatant was removed, and the cell pellets resuspended in PBS at a final volume of 1,000 $\mu \mathrm{l}$ supplemented with PMAxx to obtain a final dye concentration of 50, 75, and $100 \mu \mathrm{M}$. After PMAxx addition, the samples were incubated at $200 \mathrm{rpm}$ in the dark at room temperature or $40^{\circ} \mathrm{C}$ for $10-60 \mathrm{~min}$. Stained samples were subsequently exposed to blue-light PMA-Lite LED photolysis (Interchim, Montluçon, France) for $15 \mathrm{~min}$. In parallel, $10 \mathrm{ml}$ of inoculated PWW was taken from each flask to determine the level of total bacteria by qPCR. Bacteria cells were concentrated by centrifugation $\left(4,000 \mathrm{rpm}, 4^{\circ} \mathrm{C}, 10 \mathrm{~min}\right)$. The supernatant was discarded, and untreated and PMAxx-treated pellets were kept at $-20^{\circ} \mathrm{C}$ until DNA genomic extraction.

\section{EMA + PMAxx v-qPCR}

Ethidium monoazide (Biotium, Hayward, CA, United States) was dissolved in sterile water to obtain $2 \mathrm{mM}$ stock solution and stored at $-20^{\circ} \mathrm{C}$ in the dark until used. Following the same procedure as previously described, three separate flasks of PWW $(50 \mathrm{ml})$ were inoculated with a L. monocytogenes cocktail of live, heat-treated, and chlorine-treated cells. Ten milliliters from each flask was centrifuged, the supernatants discarded, and the pellets treated with a combination of $10 \mu \mathrm{M}$ EMA and $75 \mu \mathrm{M}$ PMA, incubated at room temperature and $40^{\circ} \mathrm{C}$ and activated with blue-light PMA-Lite LED photolysis as previously described. The total bacteria were also determined by qPCR, as described above.

\section{Culturable Bacteria}

The concentration of $L$. monocytogenes $(\mathrm{cfu} / \mathrm{ml})$ in each of the different assays was confirmed by plating. Serial 10-fold dilutions were made in BPW (2 g/l; Oxoid) and plated in Oxford agar (Scharlau). Colonies were counted after $24 \mathrm{~h}$ of incubation at $37^{\circ} \mathrm{C}$.

\section{PWW From an Industrial Setting}

Samples of PWW were taken in an industrial processing line (Cuenca, Spain) of shredded iceberg lettuce washed in a large washing tank containing about 3,000 l of PWW. A residual concentration of $10 \mathrm{mg} / \mathrm{l}$ of chlorine was set to maintain 
TABLE 1 | Physicochemical and microbiological characteristics of the process wash water (PWW) at different sampling times including free chlorine (10 mg/l), pH, chemical oxygen demand (COD), temperature ( $\left.\mathrm{T}^{\mathrm{a}}\right)$, oxidation-reduction potential (ORP), and total counts (log cfu/100 ml).

\begin{tabular}{|c|c|c|c|c|c|c|}
\hline Sampling time & Free chlorine (mg/l) & pH & COD (mg/l) & $\mathbf{T}^{\mathbf{a}}$ & ORP & Total count (log $\mathrm{cfu} / 100 \mathrm{ml})$ \\
\hline 8:00 & 12.6 & 6.6 & $537 \pm 11$ & 4.0 & 818 & 2.4 \\
\hline 10:00 & 14.6 & 6.5 & $503 \pm 10$ & 3.8 & 821 & 2.3 \\
\hline $10: 30$ & 10.9 & 6.6 & $382 \pm 20$ & 3.8 & 807 & 2.6 \\
\hline 11:00 & 9.0 & 6.5 & $469 \pm 19$ & 4.3 & 783 & 2.5 \\
\hline
\end{tabular}

the microbiological quality of the water. The washing was performed by immersion of cut lettuce for $30 \mathrm{~s}$ in the chlorinated water followed by a shower rinse with tap water for $30 \mathrm{~s}$. The physicochemical and microbiological characteristics of the PWW were monitored each hour over $4 \mathrm{~h}$ (Table 1). The physicochemical analysis included $\mathrm{pH}$, organic matter measured as COD, temperature, and oxidation-reduction potential (ORP) as well as free chlorine measurements determined as previously described (Tudela et al., 2019).

For microbiological analyses, three water samples (1 1 each) per sampling time were taken. Samples were collected and processed, and levels of culturable bacterial populations enumerated as previously described (Tudela et al., 2019). For viable total bacteria, qPCR of EMA + PMAxx-treated samples was performed following the protocol previously described. Water samples $(200 \mathrm{ml}$ each) were vacuum filtered through sterile cellulose nitrate filters $(0.45 \mu \mathrm{m})$. Filters were placed in falcon tubes $(50 \mathrm{ml})$ containing $20 \mathrm{ml}$ of PBS + Tween 80 ( $1 \mathrm{ml} / \mathrm{l}$; Sigma-Aldrich, Saint Louis, United States) and shaken in a vortex for $2 \mathrm{~min}$. After that, the filters were discarded and the tubes centrifuged for $10 \mathrm{~min}$ at 4,000 rpm. Then, the pellet was resuspended in sterile distilled water $(1 \mathrm{ml})$ and transferred to clear transparent microtubes $(2 \mathrm{ml})$. Then, the $\mathrm{v}$-qPCR procedure was carried out as previously described. Cell pellets were stored at $-20^{\circ} \mathrm{C}$ until DNA analysis.

\section{DNA Extraction and qPCR Procedure}

Genomic DNA was extracted using the MasterPure MM $^{\mathrm{TM}}$ complete DNA and RNA Purification Kit (Epicentre, Madison, United States), according to the manufacturer's indications. The quality and concentration of DNA extracts were determined by spectrophotometric measurement at 260/280 and 260/230 nm using a NanoDrop ${ }^{\circledR}$ ND-1000 UV-Vis spectrophotometer (Thermo Fisher Scientific, Inc., Waltham, MA, United States). Quantitative real-time PCR and data analysis were performed using an ABI 7500 Sequence Detection System (ABI, Applied Biosystems, Madrid, Spain). For L. monocytogenes, the primer and probe concentrations as well as the cycling parameters and conditions for reactive quantification were as previously reported (Rodriguez-Lázaro et al., 2004). In the case of total bacteria, prime concentrations, cycling parameters, and amplification and detection conditions were as previously described (Truchado et al., 2019). The limit of detection (LOD) was based on the cycle threshold $(\mathrm{Ct})$ value of the last detectable standard.

The samples with $\mathrm{Ct}$ values higher than LOQ were classified as non-determined, while $\mathrm{Ct}$ values lower than LOQ were classified as positive. LOD was determined to be $\mathrm{Ct}=37$
(23 cfu per reaction) for L. monocytogenes and $\mathrm{Ct}=34$ (85 cfu per reaction) for total bacteria.

\section{Statistical Analysis}

All experiments were performed at least in duplicate. Calculation and graphical representation of the median and interquartile range (IQR) of $\mathrm{Ct}$ values were performed using Sigma Plot 13 Systat Software, Inc. (Addlink Software Scientific, S.L. Barcelona, Spain). Total bacteria levels evaluated by plate count and molecular techniques were $\log 10$ transformed. IBM SPSS Statistics 25 was used for statistical analyses. Except when stated otherwise, $P$ values below 0.05 were considered statistically significant. Shapiro-Wilk test was performed to assess the normality of the data $(P>0.05)$. Mann-Whitney $U$ test was used to examine the differences among treatments.

\section{RESULTS AND DISCUSSION}

\section{Viability of $L$. monocytogenes Cells Using Flow Cytometry}

Flow cytometry was used to determine the proportions of L. monocytogenes cells at different states (dead, viable, and intermediate) in untreated and chlorine-treated PWW. Flow cytometry analysis allows the detection of VBNC cells that appear as double-stained cells, indicating that they are still alive but their cell membranes are compromised (Stiefel et al., 2015). This double staining allowed us to establish clearly the population of VBNC cells as shown in Figure 1, in which the potential VBNC cells can be visualized in the Q2 quadrant.

To compare the results obtained by the flow cytometry method with the plate count method, the values obtained by the plate count method were transformed into a percentage. As expected, $100 \%$ of culturable cells were obtained for the untreated PWW samples while in the treated PWW samples, it was estimated that $99.9 \%$ of the treated cells were dead and not able to grow in the culture medium. However, the flow cytometry methodology estimated that only $65.7 \%$ of the cells in the treated PWW were dead, 6.9\% were VBNC, and $27.4 \%$ of bacteria were completely viable (Table 2 ). These results could indicate that by the flow cytometry method, bacteria that are not viable are estimated as cultivable. Our results are similar to those obtained by Nocker et al. (2016) with pure cultures of E. coli, in which a loss of cultivability of the bacteria with the use of chlorine was detected before any damage in their cell membrane was shown. This is probably because other cellular components were affected by chlorine besides the membrane, 

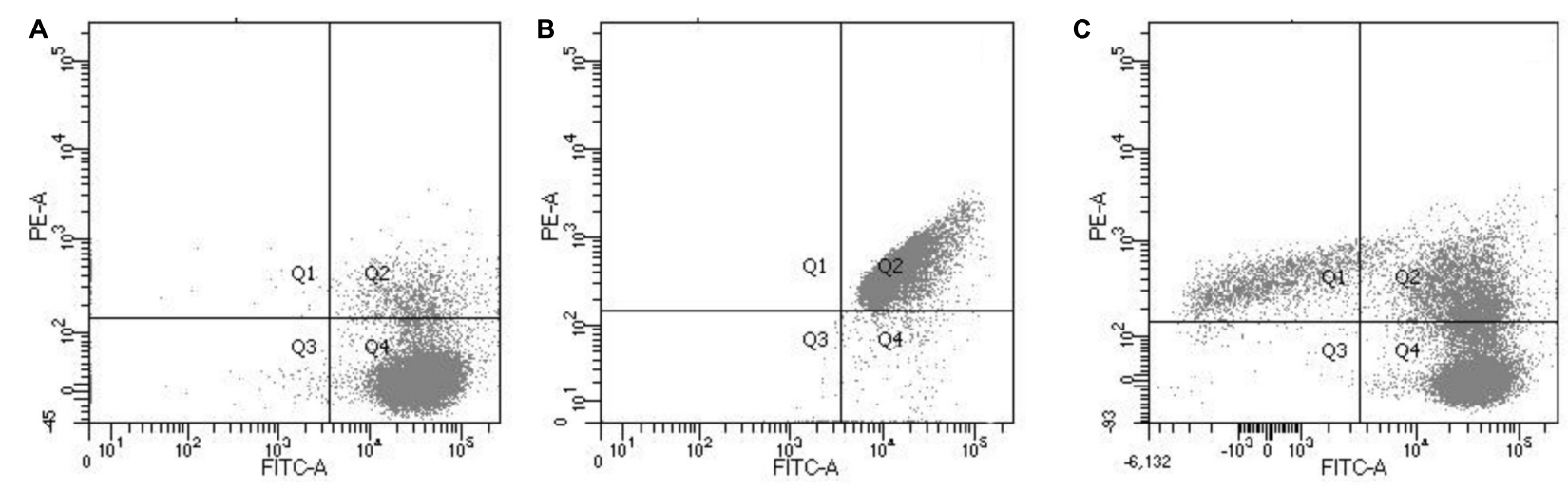

FIGURE 1 | Flow cytometric analysis showing live L. monocytogenes cells stained with green fluorescent SYTO 9 (A), dead L. monocytogenes cells (isopropanol treated) stained with red fluorescent $\mathrm{PI}(\mathbf{B})$ and $\mathbf{( C )}$ a mix culture of live and dead L. monocytogenes cells. The Q1 quadrant corresponds with the cells stained with propidium iodine red fluorescent signal (FL2 at $630 \mathrm{~nm}$; dead cells). The green fluorescent signal (FL1 at $520 \mathrm{~nm}$ ) of the Q4 corresponds with the live cells. The Q2 quadrant corresponds to the double-stained cells (membrane-compromised cells or VBNC) and the Q3 with the non-stained cells.

TABLE 2 | Percentage of viable, viable but non-culturable (VBNC), and dead cells of a six-strain cocktail of Listeria monocytogenes untreated and treated with chlorine (10 mg/L) determined by plate count and flow cytometry methods.

\begin{tabular}{|c|c|c|c|c|}
\hline \multirow[b]{2}{*}{ Methodology } & \multirow[b]{2}{*}{ Treatments } & \multicolumn{3}{|c|}{ Physiological Cell Stage (\%) } \\
\hline & & Viable & VBNC & Dead \\
\hline \multirow[t]{2}{*}{ Plate Count } & Untreated & 100.0 & & 0.0 \\
\hline & Treated & 0.0 & & 99.9 \\
\hline \multirow[t]{2}{*}{ Flow cytometry } & Untreated & $89.6 \pm 2.3$ & $7.8 \pm 1.0$ & $2.6 \pm 1.2$ \\
\hline & Treated & $27.4 \pm 3.3$ & $6.9 \pm 0.1$ & $65.7 \pm 3.3$ \\
\hline
\end{tabular}

such as proteins and lipids (Ersoy et al., 2019), which already make the cells non-viable even if their membranes were not affected. When the two methodologies were compared, the percentage of viable detected cells was higher in the flow cytometry method, which could indicate that flow cytometry could overestimate the percentage of viable cells. For the use of the flow cytometry method to determine VBNC cells, it could be necessary to use other markers of cell damage (DNA, proteins, and lipids) than the membrane. Nocker et al. (2016) observed that in samples of drinking water from a water treatment plant, there were cultivable bacteria that appeared as dead or VBNC by the flow cytometry method, in disagreement with our results. As these authors indicated, this fact could be due to the more heterogeneous natural microbiota with different susceptibilities to the disinfectant in water samples. In our study, due probably to the differences in the natural microbiota from lettuce, the results differed.

Taking into account the complex composition of the PWW, with high organic matter content and interfering compounds, the fluorescent dyes were not able to differentiate among the physiological stage of the different bacteria species. Based on the results obtained, the flow cytometry was not a suitable methodology to distinguish between viable and dead cells in PWW. Several studies have suggested the use of flow cytometry as an accurate analytical tool to determine the viability against sanitizers of the foodborne pathogenic bacteria (Nocker et al., 2016; Ersoy et al., 2019). However, these studies were mostly performed using tap water or pure cultures, without considering the complex composition of PWW in industrial settings (Gombas et al., 2017).

\section{Viability of $L$. monocytogenes Cells Using v-qPCR Techniques Combined With PMAxx}

In general, PMA concentrations of $50 \mu \mathrm{M}$ have been reported to be the optimal concentration for the efficient differentiation between live and dead cells without affecting the viability of L. monocytogenes cells (Kragh et al., 2020). However, when complex matrixes, such as PWW, are used, the concentration of PMAxx needs to be optimized to avoid any impact on cell viability. Preliminary experiments performed to determine the optimal concentration of PMAxx showed that when $50 \mu \mathrm{M}$ of PMAxx was added to PWW, the PCR signal of dead cells was not fully discriminative (data not shown). One reason could be the presence of organic matter in the PWW, which might interfere with the photoreactive DNA dye, reducing its ability to bind to the DNA of the dead cells. Based on these results, two higher concentrations of PMAxx (75 and $100 \mu \mathrm{M})$ were tested. The quantitative PCR Ct values of heat-killed L. monocytogenes treated with 75 and $100 \mu \mathrm{M}$ PMAxx concentrations were not significantly different (Figure 2A). However, a toxicity effect was observed in the live cells when a higher concentration of the dye was used (Figure 2B). Therefore, to avoid any impact on the 


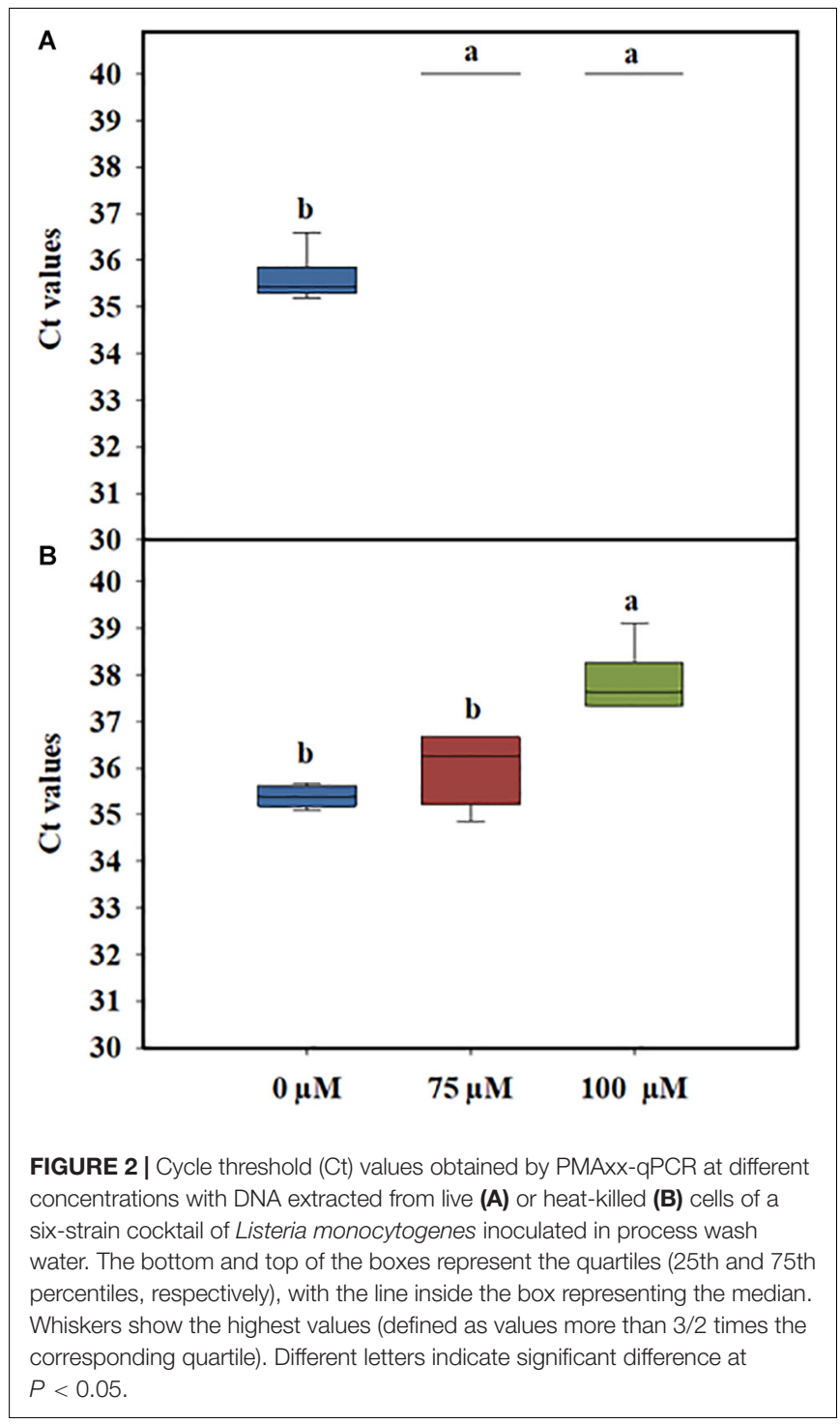

viability of the L. monocytogenes cells, the lowest concentration $(75 \mu \mathrm{M})$ of PMAxx was selected for further analysis.

Several studies have focused on the optimization of methodologies able to discriminate between live and dead cells of pathogenic bacteria such as Xylella fastidiosa, Vibrio parahaemolyticus, and Clavibacter michiganensis ssp. michiganensis in complex matrixes such as plants, shrimp, and seed tomato, respectively (Han et al., 2018; Cao et al., 2019b; Sicard et al., 2019). Most of these studies evidence the good discriminative effect of PMAxx when compared to PMA between live and dead cells in complex matrixes. However, as far as we know, differentiation between live and dead L. monocytogenes in PWW has not been accomplished.

\section{v-qPCR Combined With PMAxx + EMA}

Laboratory-scale experiments were performed to study the mode of action by which chlorine killed L. monocytogenes cells and whether or not the membrane integrity of the cells was affected. It has been accepted that chlorine and other chemical sanitizers usually inactivate the bacterial cell by the disruption of the cytoplasmic membrane (Venkobachar et al., 1997; Nocker et al., 2007). However, it is essential to determine the suitability of PMAxx to differentiate between live and dead cells when chlorine treatments are applied. In these experiments, PCR amplification of dead L. monocytogenes cells killed by heat treatment was compared with those killed by chlorine. The initial conditions used for this comparison were those previously recommended to discriminate dead L. monocytogenes, including $30 \mathrm{~min}$ of dye incubation at $40^{\circ} \mathrm{C}$ (Nkuipou-Kenfack et al., 2013). As expected, L. monocytogenes DNA activated with PMAxx $(75 \mu \mathrm{M})$ and isolated from heat-treated L. monocytogenes did not show amplification in the qPCR. However, the PCR signal of L. monocytogenes DNA activated with PMAxx $(75 \mu \mathrm{M})$ obtained from chorinetreated cells was not completely inactivated, showing a $\mathrm{Ct}$ value below the LOD (Figure 3). Our results agree with a previous study that observed that PMA-qPCR assay (PMA at $50 \mu \mathrm{M}$ for $20 \mathrm{~min}$ of incubation at $37^{\circ} \mathrm{C}$ ) did not reduce the signal of chlorine-killed cells of E. coli O:157 H7 $\left(10^{4} \mathrm{cfu} / \mathrm{ml}\right)$ artificially inoculated in drinking water (Cao et al., 2019a). Based on these results, new experiments were performed under different conditions of time/temperature for the incubation of the DNA with the dye. However, none of the tested combinations improved previous results obtained (data not shown).

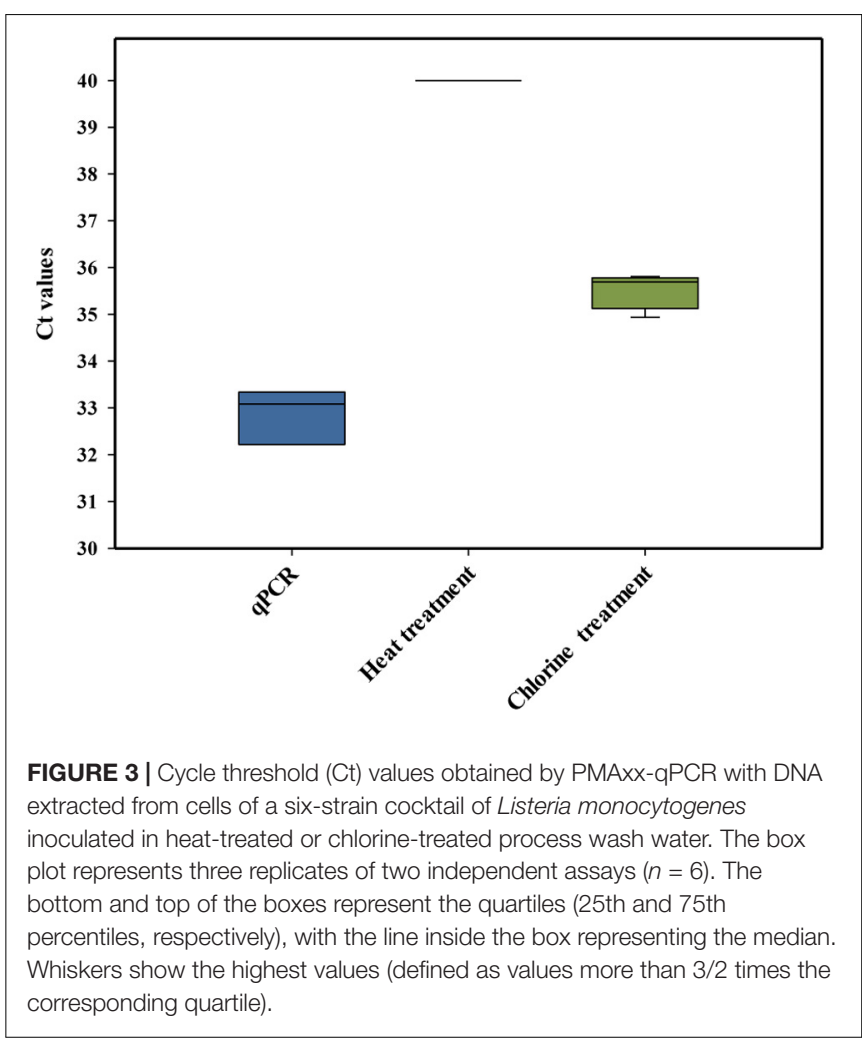




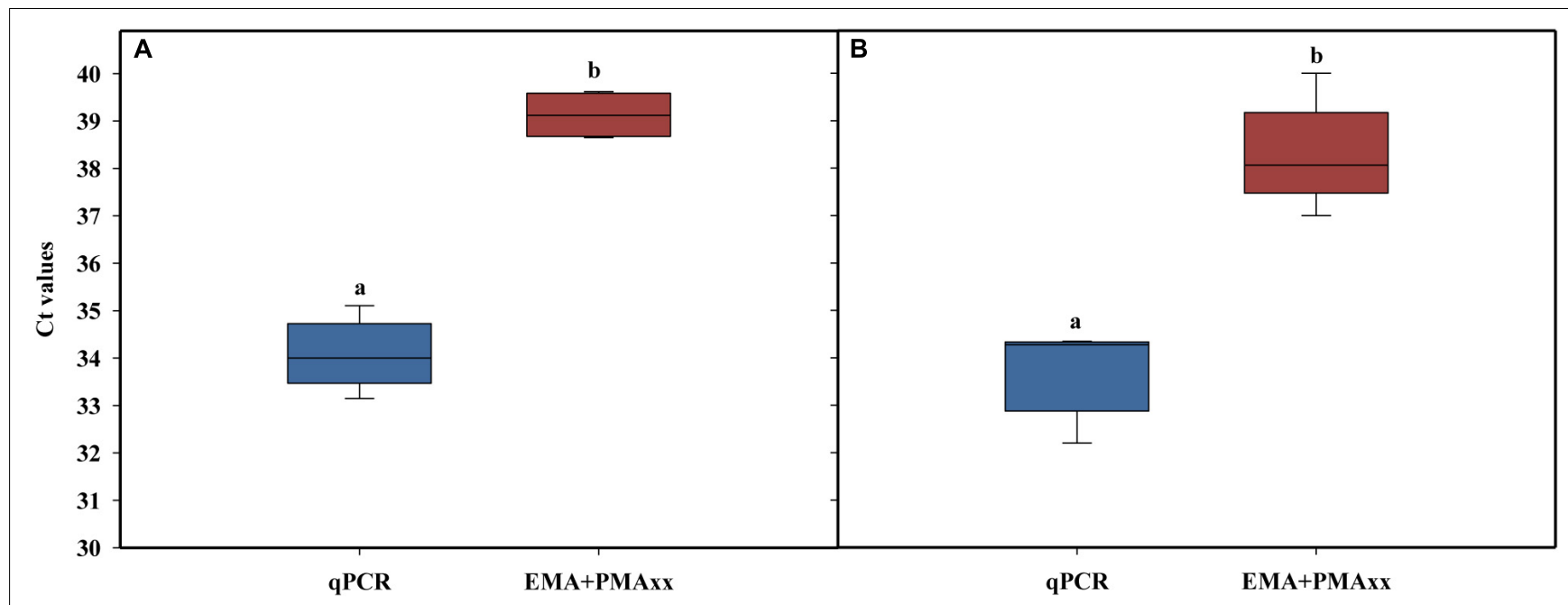

FIGURE 4 | Effect of EMA + PMAxx incubation time on cycle threshold values obtained in qPCR with DNA extracted from dead cells of a six-strain cocktail of Listeria monocytogenes inoculated in heat-treated or chlorine-treated process wash water. Time of incubation was 40 min (A) and 60 min (B). Different letters denote significant differences $(P<0.05)$. The box plot represents three replicates of two independent assays $(n=6)$. The bottom and top of the boxes represent the quartiles (25th and 75th percentiles, respectively), with the line inside the box representing the median. Whiskers show the highest values excluding outliers, and dots represent outliers (defined as values more than $3 / 2$ times the corresponding quartile).

The results indicated that there was an overestimation of the live cells because some dead cells could still be quantified (falsepositive results) after the chlorine treatment, mostly due to the presence of an intact membrane. A similar conclusion was also achieved by Virto et al. (2005) who observed that membrane damage is not the only event involved in the inactivation of bacteria by chlorine. These authors also highlighted that the presence of organic matter could play an important role in the accessibility of chlorine to the bacteria, influencing their resistance. Based on these findings, the PMAxx-qPCR method was not considered a suitable approach to differentiate between live and dead L. monocytogenes cells present in PWW treated with chlorine.

The alternative method studied was EMA combined with PMAxx, to detect both membrane integrity and active metabolism (Codony, 2014; Codony et al., 2015; Agustí et al., 2017). Several authors have suggested that cell viability should include cells that have intact, functional, and active membranes (Codony et al., 2015). Some studies related to membrane integrity reported that the combination of EMA and PMA reduced the DNA signal from dead cells (intact and damage

TABLE 3 | Listeria monocytogenes counts inoculated in process wash water detected by qPCR combined or not with EMA + PMAxx at two incubation times.

\begin{tabular}{lcc}
\hline Time of incubation (min) & \multicolumn{2}{c}{ L. monocytogenes (log cfu/ml) } \\
\cline { 2 - 3 } & qPCR & EMA + PMAxx-qPCR \\
\hline 40 & $4.14 \pm 0.10 \mathrm{a}$ & $3.83 \pm 0.11 \mathrm{a}$ \\
60 & $4.34 \pm 0.02 \mathrm{a}$ & $3.29 \pm 0.06 \mathrm{~b}$ \\
\hline
\end{tabular}

Values represent the mean \pm standard deviations for three independent replicates. membrane) and live cells with inactive membranes (Codony et al., 2015). This method is based on the EMA properties, which accumulate in dormant cells that lack the metabolic ability to offset its uptake using active mechanisms such as efflux pumps. Concentrations of $75 \mu \mathrm{M}$ of PMAxx and $10 \mu \mathrm{M}$ of EMA were used followed by incubation at $40^{\circ} \mathrm{C}$ at two incubation times

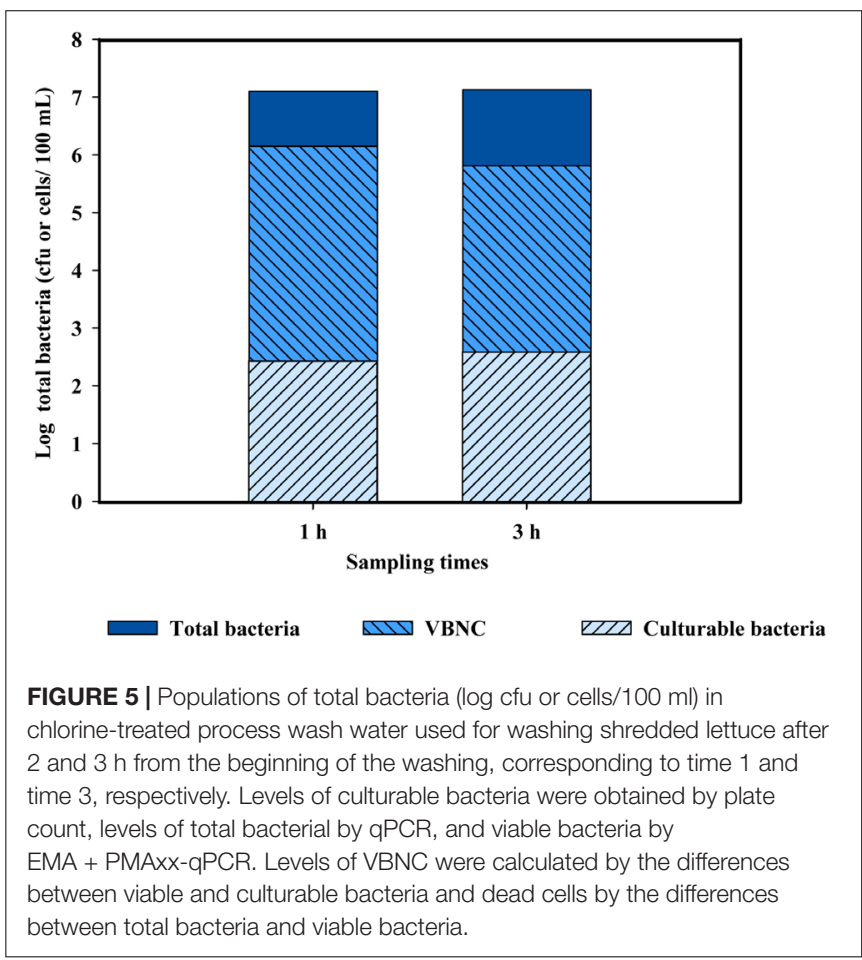


(40 and $60 \mathrm{~min}$ ) and a 15-min light exposure. The results showed that, independently of incubation time, the combination of the two photoreactive dyes (PMAxx and EMA) reduced the amplification of dead cells after chlorine treatment above the LOD (Ct value > 37; Figure 4). When the two incubation times were compared, a slight increase in the $\mathrm{Ct}$ values was observed when $60 \mathrm{~min}$ was applied versus $40 \mathrm{~min}(\mathrm{Ct}$ value $=39$ and 37, respectively). However, it should be considered that a long incubation time might have a negative effect on the viability of L. monocytogenes cells inoculated in PWW. The differences between the levels of L. monocytogenes enumerated by qPCR and EMA + PMAxx-qPCR are shown in Table 3. Based on these results, an incubation time of 40 min was selected. The latest studies demonstrated that the commercial PEMAX reagent (a new commercial reagent that combines both EMA and PMA) is suitable in food matrixes and complex environmental samples, avoiding the overestimation of the most common methodologies (Agustí et al., 2017; Daranas et al., 2018).

\section{Validation of the Detection and Quantification Method for VBNC Cells}

The detection method selected, EMA + PMAxx-qPCR, was validated in PWW samples obtained in an industrial processing line where shredded lettuce was washed with chlorine. Based on the results obtained, no significant changes in the concentration of free chlorine and $\mathrm{pH}$ were observed along with the sampling interval that was able to control the accumulation of bacteria in the PWW, maintaining a total count below 3 log units (Table 1). Similar results have been previously described in several industrial washing lines (López-Gálvez et al., 2019; Tudela et al., 2019).

When the levels of total bacteria present in PWW were quantified, the results obtained by cultivation-based methods were very different than those based by molecular-based techniques (both qPCR and EMA + PMAxx-qPCR). Several studies have reported that the use of plate count methods leads to an underestimation of the total bacterial levels in environmental samples, mostly due to the presence of cells in the VBNC state (Rastogi et al., 2010; Truchado et al., 2019). The results obtained indicate that chlorine (10 mg/l) induced bacteria into a VBNC state (Figure 5). Only slight differences were observed between the two sampling points ( 1 and $3 \mathrm{~h}$ ). These results agree with those of Highmore et al. (2018) who demonstrated that the use of chlorine induced cells of Salmonella enteritidis and L. monocytogenes into a VBNC state. However, the conditions applied in this referenced study (Highmore et al., 2018) did not represent real conditions of a fresh-cut processing line, which include the presence of high concentrations of organic matter and background microbiota in the PWW. This is the first study showing the induction of the VBNC state of bacteria cells present in PWW when water was disinfected with chlorine in industrial settings.

\section{CONCLUSION}

The v-qPCR combined with the two DNA amplificatory inhibitors (EMA and PMAxx) represents the optimization technique for the detection and quantification of cells in the VBNC state. The use of these photoreactive DNA-dye combinations (EMA and PMAxx) yields a more accurate estimation of the L. monocytogenes viable cells present in PWW than other methodologies tested, such as flow cytometry and PMAxx-qPCR. Concentrations of $10 \mu \mathrm{M}$ EMA and $75 \mu \mathrm{M}$ PMAxx and incubation at $40^{\circ} \mathrm{C}$ for $40 \mathrm{~min}$ followed by a 15 min light exposure allowed the inactivation of most of the dead cells. The validation of the method in an industrial setting showed that the methodology optimized could significantly distinguish dead and VBNC cells in PWW treated with chlorine. This method can be considered as a rapid and reliable one recommended for the detection of VBNC cells in complex water matrixes such as those of the food industry. However, complete discrimination between dead and VBNC cells was not achieved, which led to a slight overestimation on the percentage of VBNC cells in the PWW, mostly due to the complex composition of this type of wash water. The verification of the methodology optimized with different sanitizers is worthy of being investigated.

\section{DATA AVAILABILITY STATEMENT}

The raw data supporting the conclusions of this article will be made available by the authors, without undue reservation, to any qualified researcher.

\section{AUTHOR CONTRIBUTIONS}

PT, MG, and AA designed this experiment. PT conducted the molecular lab work and data analysis. ML conducted the cytometry flow lab work and data analysis. PT drafted the manuscript under the advisement of AA. All authors met to develop methods used for conducting the study and read the draft and provided feedback.

\section{ACKNOWLEDGMENTS}

The authors are thankful for the financial support from the Center for Produce Safety Grant Agreement (Projects 2018 RFP), the MINECO (Project AGL2016-75878-R), and the Fundación Séneca (19900/GERM/15). The technical assistance of Silvia Andújar and Natalia Hernández was very much appreciated. The authors acknowledge support of the publication fee by the CSIC Open Access Publication Support Initiative through its Unit of Information Resources for Research (URICI). 


\section{REFERENCES}

Agustí, G., Fittipaldi, M., and Codony, F. (2017). False-Positive viability PCR results: an association with microtubes. 2017. Curr. Microbiol. 74, 377-380. doi: 10.1007/s00284-016-1189-3

American Public Health Association [APHA] (1998). Standard Methods for Examination of Water and Wastewater, 20th Edn. Washington, DC: American Public Health Association.

Cao, Y., Zhou, D., Li, R., Yu, Y., Xiau, X., Zhou, A., et al. (2019a). Molecular monitoring of disinfection efficacy of Escherichia coli O157:H7 in bottled purified drinking water by quantitative PCR with a novel dye. J. Food Process Preserv. 43:e13875. doi: 10.1111/jfpp.13875

Cao, X., Zhao, L., Zhang, J., Chen, X., Shi, L., Famg, X., et al. (2019b). Detection of viable but nonculturable Vibrio parahaemolyticus in shrimp samples using improved real-time PCR and real-time LAMP methods. Food Control 103, $145-115$.

Codony, F. (2014). Procedimiento Para la Detección de Células Vivas, Con las Membranas Celulares Íntegras y Funcionales, Mediante Técnicas de Amplificación de Ácidos Nucleicos. Spanish patent, N ES2568527B1.

Codony, F., Agustí, G., and Allué-Guardia, A. (2015). Cell membrane integrity and distinguishing between metabolically active and inactive cells as means of improving viability PCR. Mol. Cell Probes. 29, 190-192. doi: 10.1016/j.mcp. 2015.03.003

Daranas, N., Bonaterra, A., Francés, J., Cabrefiga, J., Montesinos, E., and Badosa, E. (2018). Monitoring viable cells of the biological control agent Lactobacillus plantarum PM411 in aerial plant surfaces by means of a strain-specific viability quantitative PCR method. Appl. Environ. Microbiol. 84, e107-e118. doi: 10. 1128/AEM.00107-18

Dong, K., Pan, H., Yang, D., Rao, L., Zhao, L., Wang, Y., et al. (2020). Induction, detection, formation, and resuscitation of viable but non-culturable state microorganisms. Compr. Rev. Food Sci. Food Safety 19, 149-183. doi: 10.3389/ fmicb. 2018.02728

Dorn-In, S., Gareis, M., and Schwaiger, K. (2019). Differentiation of live and dead Mycobacterium tuberculosis complex in meat samples using PMA-qPCR. Food Microbiol. 84:103275. doi: 10.1016/j.fm.2019.103275

Ersoy, Z. G., Dinc, O., Cinar, B., Gedik, S. T., and Dimoglo, A. (2019). Comparative evaluation of disinfection mechanism of sodium hypochlorite, chlorine dioxide and electroactivated water on Enterococcus faecalis. LWT 102, 205-213. doi: 10.1016/j.lwt.2018.12.041

European Food Safety Authority [EFSA] (2018). Listeria monocytogenes contamination of ready to eat foods and the risk for human health in the EU. EFSA J. 16, 5134-5307.

Fida, T. T., Moreno-Forero, S. K., Breugelmans, P., Heipieper, H. J., Röling, W. F., and Springael, D. (2017). Physiological and transcriptome response of the polycyclic aromatic hydrocarbon degrading Novosphingobium sp. LH128 after inoculation in soil. Environ. Sci. Technol. 51, 1570-1579. doi: 10.1021/acs.est. $6 \mathrm{~b} 03822$

Gil, M. I., and Allende, A. (2018). "Water and wastewater use in the fresh produce industry: food safety and environmental implications," in Quantitative Methods for Food Safety and Quality in the Vegetable Industry. Food Microbiology and Food Safety, eds F. Pérez-Rodríguez, P. Skandamis, and V. Valdramidis, (Switzerland: Springer), 59-77.

Gombas, D., Luo, Y., Brennan, J., Shergill, G., Petran, R., Walsh, R., et al. (2017). Guidelines to validate control of cross-contamination during washing of freshcut leafy vegetables. J. Food Protect. 80, 312-330. doi: 10.4315/0362-028X.JFP16-258

Han, S., Jiang, N., Lv, Q., Kan, Y., Hao, J., Li, J., et al. (2018). Detection of Clavibacter michiganensis subsp. michiganensis in viable but nonculturable state from tomato seed using improved qPCR. PLoS One 13:e0196525. doi: 10.1371/journal.pone.0196525

Highmore, C. J., Warner, J. C., Rothwell, S. D., Wilks, S. A., and Keevil, C. W. (2018). Viable-but nonculturable Listeria monocytogenes and Salmonella enterica serovar thompson induced by chlorine stress remain infectious. mBio 9:e00540-18. doi: 10.1128/mBio.00540-18

Kragh, M. L., Thykier, M., and Truelstrup Hansen, L. (2020). A long-amplicon quantitative PCR assay with propidium monoazide to enumerate viable Listeria monocytogenes after heat and desiccation treatments. Food Microbiol. 86:103310. doi: 10.1016/j.fm.2019.103310
Léonard, L., Bouarab Chibane, L., Ouled Bouhedda, B., Degraeve, P., and Oulahal, N. (2016). Recent advances on multi-parameter flow cytometry to characterize antimicrobial treatments. Front. Microbiol. 7:1225. doi: 10.3389/fmicb.2016. 01225

López-Gálvez, F., Tudela, J. A., Allende, A., and Gil, M. I. (2019). Microbial and chemical characterization of commercial washing lines of fresh produce highlights the need for process water control. Innov. Food Sci. Emerg. Technol. 51, 211-219. doi: 10.1016/j.ifset.2018.05.002

Makino, S. I, Kii, T., Asakura, H., Shirahata, T., Ikeda, T., Takeshi, K., et al. (2000). Does enterohemorrhagic Escherichia coli O157:H7 enter the viable but nonculturable state in salted salmon roe? Appl. Environ. Microbiol. 66, 5536-5539. doi: 10.1128/aem.66.12.5536-5539.2000

Nkuipou-Kenfack, E., Engel, H., Fakih, S., and Nocker, A. (2013). Improving efficiency of viability-PCR for selective detection of live cells. J. Microbiol. Method 93, 20-24. doi: 10.1016/j.mimet.2013. 01.018

Nocker, A., and Camper, A. K. (2009). Novel approaches toward preferential detection of viable cells using nucleic acid amplification techniques. FEMS Microbiol. Lett. 291, 137-142. doi: 10.1111/j.1574-6968.2008.01429.x

Nocker, A., Cheswick, R., de la Rochere, P. M. D., Denis, M., Leziart, T., and Jarvis, P. (2016). When are bacteria dead? A step towards interpreting flow cytometry profiles after chlorine disinfection and membrane integrity staining. Environ. Technol. 38, 891-900. doi: 10.1080/09593330.2016.1262463

Nocker, A., Cheung, C. Y., and Camper, A. K. (2006). Comparison of propidium monoazide with ethidium monoazide for differentiation of live vs. dead bacteria by selective removal of DNA from dead cells. J. Microbiol. Method 67, 310-320. doi: 10.1016/j.mimet.2006.04.015

Nocker, A., Sossa, K., and Camper, A. K. (2007). Molecular monitoring of disinfection efficacy using propidium monoazide in combination with quantitative PCR. J. Microbiol. Methods 70, 252-260. doi: 10.1016/j.mimet.2007. 04.014

Oliver, J. D. (2010). Recent findings on the viable but nonculturable state in pathogenic bacteria. FEMS Microbiol. Rev. 34, 415-425. doi: 10.1111/j.15746976.2009.00200.x

Rastogi, G., Tech, J. J., Coaker, G. L., and Leveau, J. H. (2010). A PCR-based toolbox for the culture-independent quantification of total bacterial abundances in plant environments. J. Microbiol. Method 83, 127-132. doi: 10.1016/j.mimet.2010. 08.006

Rodriguez-Lázaro, D., Hernández, M., Scortti, M., Esteve, T., Vázquez-Boland, J. A., and Pla, M. (2004). Quantitative detection of Listeria monocytogenes and Listeria innocua by real-time PCR: assessment of hly, iap and lin02483 targets and AmpliFluorTM technology. Appl. Environ. Microbiol. 70, 1366-1377. doi: 10.1128/aem.70.3.1366-1377.2004

Sicard, A., Merfa, M. V., Voeltz, M., Zeilinger, A. R., De La Fuente, L., and Almeida, R. P. P. (2019). Discriminating between viable and membrane damaged cells of the plant pathogen Xylella fastidiosa. PLoS One 14:e0221119. doi: 10.1371/ journal.pone.0221119

Stiefel, P., Schmidt-Emrich, S., Maniura-Weber, K., and Ren, Q. (2015). Critical aspects of using bacterial cell viability assays with the fluorophores SYTO9 and propidium iodide. BMC Microbiol. 15:36. doi: 10.1186/s12866-015-0376-X

Su, X., Xue, B., Wang, Y., Hashmi, M. Z., Lin, H., Chen, J., et al. (2019). Bacterial community shifts evaluation in the sediments of Puyang River and its nitrogen removal capabilities exploration by resuscitation promoting factor. Ecotoxicol. Environ. Safety179, 188-197. doi: 10.1016/j.ecoenv.2019.04.067

Truchado, P., Elsser-Gravesen, A., Gil, M. I., and Allende, A. (2020). Post-process treatments are effective strategies to reduce Listeria monocytogenes on the surface of leafy greens: a pilot study. . Int. J. Food Microbiol. 313:108390. doi: 10.1016/j.ijfoodmicro.2019.108390

Truchado, P., Gil, M. I., Kostic, T., and Allende, A. (2016). Optimization and validation of a PMA qPCR method for Escherichia coli quantification in primary production. Food Control 62, 150-156. doi: 10.1016/j.foodcont.2015.10.014

Truchado, P., Gil, M. I., Moreno-Candel, M., and Allende, A. (2019). Impact of weather conditions, leaf age and irrigation water disinfection on the major epiphytic bacterial genera of baby spinach grown in an open field. Food Microbiol. 78, 46-52. doi: 10.1016/j.fm.2018.09.015

Tudela, J. A., López-Gálvez, F., Allende, A., and Gil, M. I. (2019). Chlorination management in commercial fresh produce processing lines. Food Control. 106:106760. doi: 10.1016/j.foodcont.2019.106760 
Venkobachar, C., Iyengar, L., and Rao, A. V. S. P. (1997). Mechanism of disinfection: effect of chlorine on cell membrane functions. Water Res. 11, 727-729. doi: 10.1016/0043-1354(77)90114-2

Virto, R., Mañas, P., Álvaraz, I., Condon, S., and Raso, J. (2005). Membrane damage and microbial inactivation by chlorine in the absence and presence of a chlorine-demanding substrate. Appl. Environ. Microbiol. 71, 5022-5028. doi: 10.1128/aem.71.9.5022-5028.2005

Zhao, X., Zhong, J., Wei, C., Lin, C. W., and Ding, T. (2017). Current perspectives on viable but non-culturable state in foodborne pathogens. Front. Microbiol. 12:580. doi: 10.3389/fmicb.2017.00580
Conflict of Interest: The authors declare that the research was conducted in the absence of any commercial or financial relationships that could be construed as a potential conflict of interest.

Copyright (c) 2020 Truchado, Gil, Larrosa and Allende. This is an open-access article distributed under the terms of the Creative Commons Attribution License (CC BY). The use, distribution or reproduction in other forums is permitted, provided the original author(s) and the copyright owner(s) are credited and that the original publication in this journal is cited, in accordance with accepted academic practice. No use, distribution or reproduction is permitted which does not comply with these terms. 